\title{
Analytical model for the bond-slip behavior of corroded ribbed reinforcement
}

Karin Lundgren, Per Kettil, Kamyab Zandi Hanjari, Hendrik Schlune, Armando Soto San Roman

This is an Accepted Manuscript of an article published by Taylor \& Francis Group in Structure and Infrastructure Engineering, published online 21 December 2009, available online: http://dx.doi.org/10.1080/15732470903446993

Full reference:

Lundgren, K., Kettil, P., Zandi Hanjari, K., Schlune, H. and San Roman, A. S. (2012): Analytical model for the bond-slip behaviour of corroded ribbed reinforcement, Structure and Infrastructure Engineering, Volume 8, Issue 2, pp 157-169. http://dx.doi.org/10.1080/15732470903446993. 


\title{
Analytical model for the bond-slip behavior of corroded ribbed reinforcement
}

\author{
Karin Lundgren ${ }^{* a}$, Per Kettil ${ }^{b}$, Kamyab Zandi Hanjari ${ }^{a}$, Hendrik Schlune ${ }^{a}$, \\ Armando Soto San Roman ${ }^{\mathrm{c}}$ \\ ${ }^{a}$ Department of Civil and Environmental Engineering, Division of Structural \\ Engineering, Concrete Structures, Chalmers University of Technology, Sweden \\ ${ }^{b}$ Department of Applied Mechanics, Chalmers University of Technology, Sweden \\ ${ }^{c}$ Department of Structures, Technip Norge AS, Norway \\ * Corresponding author. Email: karin.lundgren@chalmers.se
}

\begin{abstract}
Corrosion of reinforcement affects the bond mechanism between reinforcement and concrete, and thus the anchorage. Reliable models describing this are needed especially for assessment of the load-carrying capacity of existing structures. This paper presents an analytical one-dimensional model for bond-slip response of corroded reinforcement. The proposed model is an extension of the bond-slip model given in the CEB-FIP Model Code 1990, and is practically applicable for structural analyses to determine the loadcarrying capacity of corroded structures. Furthermore, the anchorage length needed to anchor the yield force is calculated from the bond slip, using the one-dimensional bondslip differential equation. Results of the proposed model are compared to experimental results as well as results from an advanced three-dimensional finite element model. The suggested model is shown to give results that are consistent with the physical behavior.
\end{abstract}

Keywords: corrosion; bond slip; concrete; reinforcement; analytical model

\section{Introduction}

There is a growing need for reliable methods of assessing the load-carrying capacity and remaining service life of deteriorated structures to achieve optimized maintenance. One of the most common causes of deterioration of reinforced concrete structures is corrosion of steel reinforcement. The corrosion leads to volume expansion of the steel, which generates splitting stresses in the concrete, influencing the bond between concrete and reinforcement. This can lead to bond failure and subsequent collapse of the structure.

During recent years, much research concerning durability aspects of reinforced concrete has been carried out. Lifetime design and assessment based on probabilistic approaches have been developed; see e.g. Duracrete (2000). A rather common approach is to assume that the service life is ended when corrosion is initiated, which is not the case, and may lead to uneconomical large concrete covers, or that existing deteriorating structures are deemed out and must be demolished. Hence, the effects of corrosion on the load bearing capacity of the structure must be included in the lifetime design or assessment. This calls for the development of models that can be used to predict the residual strength of the corrosion damaged structure.

Corrosion of the steel reinforcement has two major effects: 1) Reduction of the effective rebar area, and 2) change of bond properties between the reinforcement and the concrete, which is the topic of this paper. This has been studied by many 
researchers; for a state-of-the-art report see fib (2000). Some researchers, e.g. Lee et al. (2002) and Bhargava et al. (2008), have proposed functions for bond capacity versus corrosion level based on experiments. Others, e.g. Coronelli (2002) and Wang and Liu (2006), have proposed analytical models for calculating the bond strength. Berra et al. (2003) and Lundgren (2005) have used detailed finite element modeling to investigate the bond mechanism for corroded bars in concrete, in particular the effect of splitting stresses induced in the concrete by the volume increase of the corrosion products. However, this type of detailed three-dimensional (3D) modeling of the region around all the reinforcement bars is impractical for analysis of complete structures. To the authors' knowledge, there is no available general simple model predicting the bond-slip behavior for corroded bars. This would be useful to have as input in structural analysis at assessment of existing structures. Therefore, a simple model that results in one-dimensional (1D) bond-slip relations for corroded reinforcement was developed and is presented in this paper.

In previous work presented by Soto San Roman (2006), the detailed 3D model of Lundgren (2005) was used for a parameter study resulting in 1D bond-slip relations for different cases and different amounts of corrosion penetration. From the results, it was noted that it was possible to obtain the bond-slip response of corroded reinforcement by shifting the bond-slip curve, see Figure 7, of uncorroded reinforcement along the slip axis, see Schlune (2006) or Lundgren et al. (2007). The shift along the slip axis depended on the degree of corrosion. Thus, the level of corrosion corresponds to a certain amount of slip. This can be explained by assuming that corrosion has an effect similar to that of pulling of a bar, i.e. in both cases splitting stresses are induced in the concrete. Based on these findings, the 1D bondslip model given in the CEB-FIP Model Code 1990, CEB (1993), was extended to include corroded reinforcement.

The purpose of this paper is to present the extension of the 1D bond-slip model given in the CEB-FIP Model Code 1990 to include corroded ribbed reinforcement. Furthermore, the effect of corrosion on the anchorage length is examined, and comparisons to test results and more detailed analyses are made. The presentation is organized as follows:

1) The basic $1 \mathrm{D}$ bond-slip differential equation is stated.

2) The 1D bond-slip model given in the CEB-FIP Model Code 1990 is reformulated into a plasticity model.

3) The model is refined with respect to the degree of confinement.

4) The effect of corrosion is introduced into the model.

5) The properties of the proposed model are discussed.

6) The numerical implementation of the model is described.

7) The proposed 1D model is compared to a 3D model and experimental results.

8) The work is concluded. 


\section{D bond-slip model for uncorroded and corroded ribbed bars}

\section{$1 D$ bond-slip differential equation}

The equilibrium equation along a reinforcement bar is

$$
\frac{\pi \cdot d^{2}}{4} \cdot \frac{d \sigma}{d x}-\pi \cdot d \cdot \tau=0
$$

where $d$ is the rebar diameter, $\sigma$ is the stress in the rebar and $\tau$ is the bond stress. The stress in the reinforcement is assumed to be in the elastic range (for the purpose of analysis of the bond-slip behavior within the anchorage length of the bar) according to

$$
\sigma=E \varepsilon, \quad \varepsilon=\frac{d u}{d x}
$$

where $E$ is the Young's modulus, $\varepsilon$ is the strain and $u$ is the displacement of the bar. The bond stress is here assumed to follow an elasto-plastic law

$$
\begin{aligned}
& \tau=D\left(s-s_{p}\right), \\
& |\tau| \leq \tau_{b}(\kappa)
\end{aligned}
$$

where $D$ is the bond stiffness, $s$ is the slip, $s_{p}$ is the plastic slip, and $\tau_{b}$ is the bond strength, which is a function of the hardening parameter $\kappa$. Here, the deformation of the surrounding concrete is neglected, and hence the displacement of the bar is equal to the slip:

$$
u=s
$$

The boundary conditions for the problem of pull-out of a bar with length $L$ with a prescribed displacement $u_{L}$ are

$\sigma(0)=0, \quad u(L)=u_{L}$

The solution of the differential equation gives the deformation and stress along the bar as well as the pull-out force.

Plasticity formulation of the bond-slip constitutive model in CEB-FIP model code 1990

The actual shape of the 1D bond strength function $\tau_{b}$ depends on the properties, the geometry and stress distribution of both the surrounding concrete and the reinforcement bar. One proposal for such a bond-slip function that tries to take the most important of these effects into account is given in the CEB-FIP Model Code 1990, CEB (1993). Here it is slightly reformulated into the format of theory of plasticity, which later allows a convenient treatment of corroded reinforcement. In addition, this makes the model applicable for reversed and cyclic loading conditions, as for example in the vicinity of developing flexural crack. However, the result of the model for reversed and cyclic loading has not yet been verified against test data. 
The first part of the bond strength curve is slightly reformulated to give an initial finite stiffness, while the rest of the equations completely follow the CEB-FIP Model Code 1990:

$$
\begin{aligned}
& \tau_{b}(\kappa)=\left(1-\left(1-2 \frac{\kappa}{s_{1}}\right)^{2}\right) \cdot \tau_{\max }, \quad 0 \leq \kappa<\frac{s_{1}}{2} \\
& \tau_{b}(\kappa)=\tau_{\max }, \quad \frac{s_{1}}{2} \leq \kappa<s_{2}-\frac{s_{1}}{2} \\
& \tau_{b}(\kappa)=\tau_{\max }-\left(\tau_{\max }-\tau_{f}\right) \cdot\left(\frac{\kappa-s_{2}+\frac{s_{1}}{2}}{s_{3}-\frac{\tau_{f}}{D}-s_{2}+\frac{s_{1}}{2}}\right), \quad s_{2}-\frac{s_{1}}{2} \leq \kappa<s_{3}-\frac{\tau_{f}}{D} \\
& \tau_{b}(\kappa)=\tau_{f}, \quad s_{3}-\frac{\tau_{f}}{D} \leq \kappa
\end{aligned}
$$

where $\tau_{\max }, \tau_{f}, s_{1}, s_{2}$ and $s_{3}$ are model parameters as given by Table 1 . Most of these parameters are chosen as in CEB (1993). The only exception is the maximum bond strength, $\tau_{\max }$, for confined concrete, which is chosen as suggested in Magnusson (2000), to better correspond also for high-strength concrete. In Figure 1, the bond-slip curve resulting from the reformulated equation (8) is compared to the one given in the CEB-FIP Model Code; as can be seen, the difference is small. Note that the maximum bond stress $\tau_{\max }$ is reached for the same slip value $s_{1}$. At this point half of the slip is plastic in the model presented here; thus the hardening parameter $\kappa$ equals $s_{1} / 2$. This is because the bond stiffness $D$ is chosen as

$$
D=\frac{2 \tau_{\max }}{s_{1}}
$$

For the uncorroded case, the hardening parameter $\kappa$ is equal to the plastic slip $s_{p}$

$$
\kappa=s_{p}
$$

where $s_{p}$ is defined by equation (4). The equations 8-11 are plotted in Figure 2 for the confined and unconfined cases as well as an intermediate interpolated curve as defined in the next paragraph. 
Bond stress

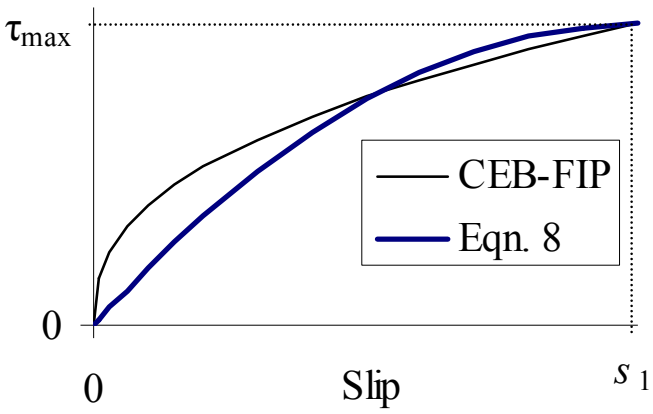

Figure 1. First part of the bond-slip curve.

Table 1. Bond-slip model parameters

\begin{tabular}{|l|c|c|c|c|}
\hline & \multicolumn{2}{|c|}{ Unconfined concrete } & \multicolumn{2}{c|}{ Confined concrete } \\
\hline & $\begin{array}{c}\text { Good bond } \\
\text { conditions }\end{array}$ & $\begin{array}{c}\text { All other bond } \\
\text { conditions }\end{array}$ & $\begin{array}{c}\text { Good bond } \\
\text { conditions }\end{array}$ & $\begin{array}{c}\text { All other bond } \\
\text { conditions }\end{array}$ \\
\hline$s_{1}[\mathrm{~mm}]$ & 0.6 & 0.6 & 1.0 & 1.0 \\
\hline$s_{2}[\mathrm{~mm}]$ & 0.6 & 0.6 & 3.0 & 3.0 \\
\hline$s_{3}[\mathrm{~mm}]$ & 1.0 & 2.5 & $\begin{array}{c}\text { Clear rib } \\
\text { spacing }\end{array}$ & $\begin{array}{c}\text { Clear rib } \\
\text { spacing }\end{array}$ \\
\hline$\tau_{\max }[\mathrm{MPa}]$ & $2.0 \sqrt{f_{c c}} *$ & $1.0 \sqrt{f_{c c}} *$ & $0.45 f_{c c}$ & $0.225 f_{c c}$ \\
\hline$\tau_{f}[\mathrm{MPa}]$ & $0.15 \tau_{\max }$ & $0.15 \tau_{\max }$ & $0.40 \tau_{\max }$ & $0.40 \tau_{\max }$ \\
\hline
\end{tabular}

$* f_{c c}$ in $\mathrm{MPa}$

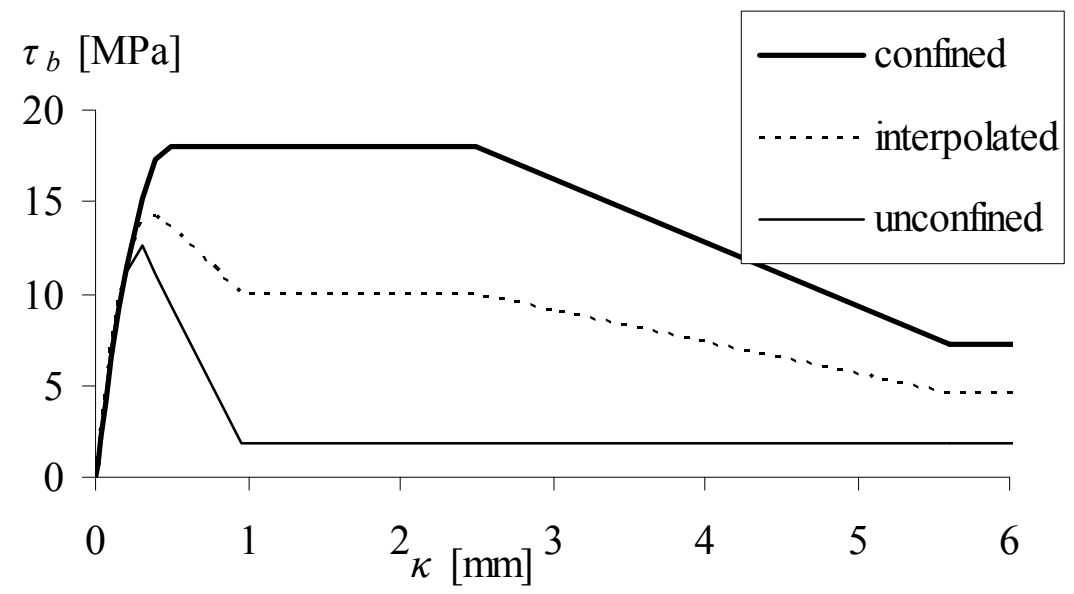

Figure 2. Bond strength plotted versus hardening parameter for good bond, an assumed clear rib spacing of $5.8 \mathrm{~mm}$ and a compressive strength of 40 $M P a$. An example of an interpolated curve is also shown; in this case the interpolation factor kuncor is 0.5 . 


\section{Interpolation between the cases "confined" and "unconfined"}

The CEB-FIP Model Code 1990 gives parameters for the extreme cases "confined" (i.e. ductile pull-out failure) and "unconfined" (i.e. brittle failure due to cover cracking induced by the radial tensile stress); see Table 1. Required cover and amount of transverse reinforcement needed to justify an assumption about confined concrete is also given in the Model Code. In the following, a method used to interpolate for intermediate cases, which often occur in practice, is described.

The bond strength versus hardening parameter curve for the intermediate case is, although the physical failure mechanisms are different, assumed to be the weighted sum of the bond-slip curves for the "confined" and "unconfined" cases, according to

$\tau_{b}=k_{\text {uncor }} \cdot \tau_{b, \text { conf }}+\left(1-k_{\text {uncor }}\right) \cdot \tau_{b, \text { unconf }}$

An example of an interpolated curve is shown in Figure 2. The interpolation factor is determined by

$k_{\text {uncor }}=\max \left\{\begin{array}{l}k_{c / d} \\ k_{A s w}\end{array}\right.$

where $k_{c / d}$ is a factor that depends on the cover to bar diameter ratio, and $k_{A s w}$ is a factor that depends on the amount of transverse reinforcement $A_{s w} / s$ (see derivation in Figure 4) according to Figure 3.

The amount of transverse reinforcement $A_{s w} / s$ that is assumed to correspond to pull-out failure, see derivation in Figure 4, is estimated from the assumptions that the transverse reinforcement yields when the maximum bond stress for pull-out failure is obtained, and that the splitting stresses equal the bond stresses. Transverse reinforcement should only be accounted for when it is efficient; therefore, the following two conditions should be fulfilled:

1. A splitting crack will cross the transverse reinforcement (may not be the case for e.g. horizontal splitting cracks between bars with small spacing), and

2. Slip of the main bar will introduce substantial strain in the transverse reinforcement (may not be the case if the transverse reinforcement is not located outside the main bars in for example a slab). 

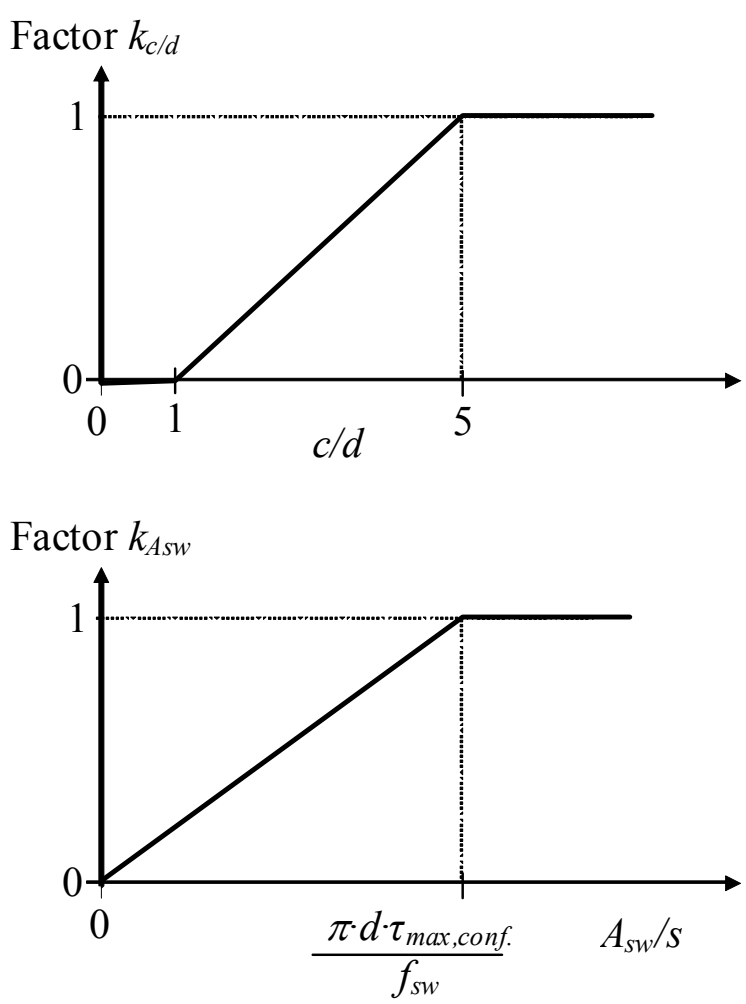

Figure 3. Factors for interpolation between "confined" and "unconfined" case.

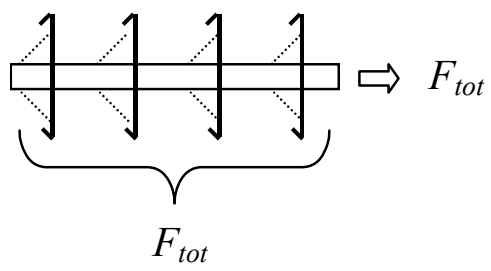

Amount of transverse reinforcement that manages to give pull-out failure:

$$
\begin{aligned}
& l \cdot \pi \cdot d \cdot \tau_{\text {max }, \text { conf } .}=l \cdot \frac{A_{s w}}{s} \cdot f_{s w} \\
& \Rightarrow \frac{A_{s w}}{s}=\frac{\pi \cdot d \cdot \tau_{\text {max }, \text { conf } .}}{f_{s w}}
\end{aligned}
$$

Figure 4. Derivation of amount of transverse reinforcement that manages to give pull-out failure.

\section{Effect of corrosion}

From the results presented by Soto San Roman (2006), it was noted that it was possible to obtain the bond-slip response of corroded reinforcement by shifting the bond-slip curve of uncorroded reinforcement along the slip axis. The explanation is the exhaustion of the confinement resistance by splitting stresses and cracking induced by the corrosion pressure, which is an effect similar to that produced by bar loading. This observation can conveniently be introduced in the plasticity formulation of the CEB-FIP bond-slip model by making the hardening parameter dependent on both the plastic slip $s_{p}$ and the corrosion penetration $x$ according to (with $s_{p}$ and $x$ having the same units, e.g. $\mathrm{mm}$ ) 
$\kappa=s_{p}+a x$

where the parameter $a$ is assumed to be a constant. This was suggested by Schlune (2006); see also Lundgren et al. (2007). This is a straightforward way to introduce the negative effect corrosion has on bond. Schlune (2006) found that the constant $a$ was around 8.1 for the analyzed cases. This value was also chosen in the analyses described in this paper. Thus, this means that a corrosion penetration of around $120 \mu \mathrm{m}$ is assumed to cause splitting stresses equivalent to those caused by a plastic slip of $1 \mathrm{~mm}$.

\section{Change of failure mode due to corrosion cracking}

For corroding reinforcement, the failure mode can change from pull-out to splitting failure, unless sufficient confinement is provided by efficient transverse reinforcement. This change of failure mode would not be included in the model if only equation (16) was used. Instead, the change of failure mode is here accounted for by an interpolation factor $k_{c o r}$ that depends on the ratio $x / x_{c r}$, where $x$ is the corrosion penetration and $x_{c r}$ is the corrosion penetration that causes cover cracking. Thus, when the cover is cracked, the remaining bond capacity depends only on the transverse reinforcement. Before the cover is cracked, the cover also contributes to the capacity. To get a numerically stable modeling, a linear decrease from the capacity including the effect of the cover to the capacity only due to the transverse reinforcement is assumed to take place from a corrosion penetration of $85 \%$ of cover cracking. The bond strength versus hardening parameter is assumed, similarly to the uncorroded case, to be the weighted sum of the bond-slip curves for the "confined" and "unconfined" cases according to

$\tau_{b}=k_{\text {cor }} \cdot \tau_{b, \text { conf }}+\left(1-k_{\text {cor }}\right) \cdot \tau_{b, \text { unconf }}$,

where the factor $k_{c o r}$ is given as shown in Figure 5. Equation 17 gives a residual strength that only depends on the amount of transverse reinforcement, and gives zero residual strength if no transverse reinforcement is present, which is a conservative assumption.

The corrosion penetration that causes cover cracking was found by curve fitting to analysis results from the detailed 3D model in Lundgren (2005), as given by the following formula:

$x_{c r}=11 \cdot\left(\frac{f_{c c}}{40}\right)^{0.8} \cdot\left(\frac{c}{d}\right)^{1.5} \cdot\left(\frac{d}{16}\right)^{0.5}$

where $x_{c r}$ is the corrosion level that cracks the cover in $\mu \mathrm{m}, f_{c c}$ is the concrete cylinder compressive strength in $\mathrm{MPa}, c$ is the concrete cover in $\mathrm{mm}$, and $d$ is the reinforcement bar diameter in $\mathrm{mm}$. In Figure 6, the suggested equation is compared to experimental data from the literature. As can be seen, reasonable agreement is found, especially considering that the scatter in experiments usually is rather large. 


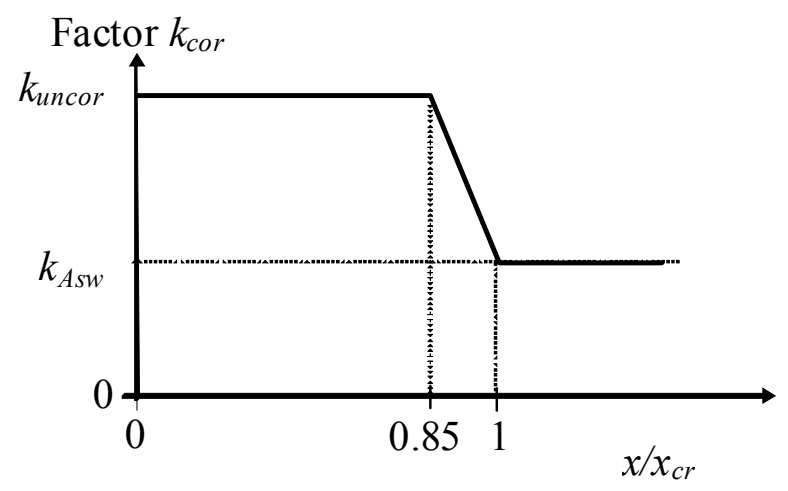

Figure 5. Factor to take a change of failure mode into account for corroding reinforcement.

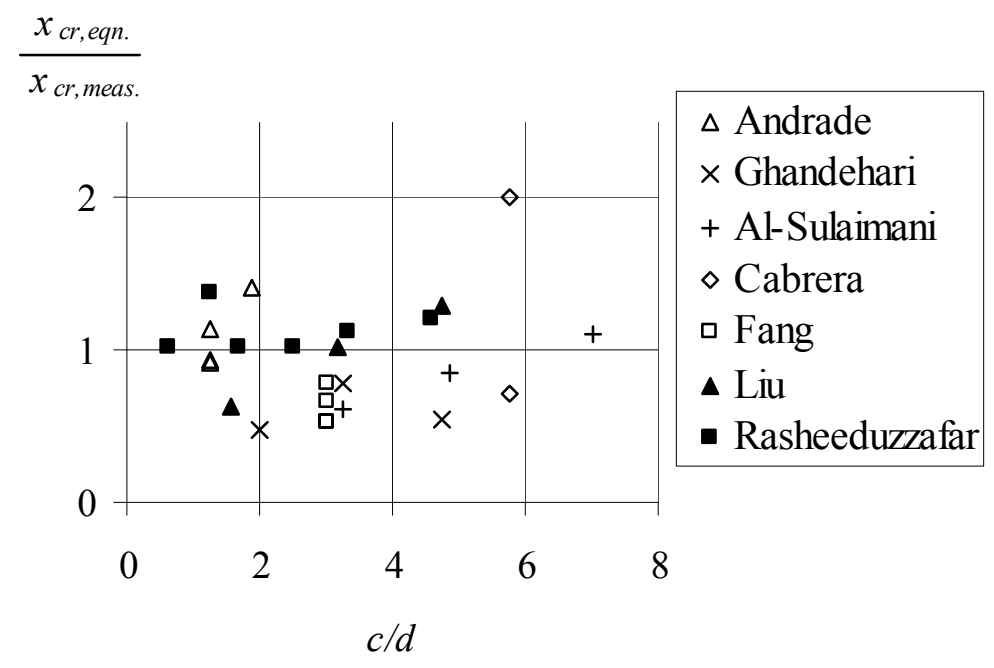

Figure 6. Results of proposed equation for corrosion penetration that causes cover cracking for experimental data in the literature. Average value of xcr,eqn/xcr,meas is 0.95 .

\section{Discussion of the model}

The formulation of the bond-slip model as a plasticity model just described is equivalent to using a "master curve" and adjusting the slip level to the amount of corrosion. This method is described in Schlune (2006), and can also be used to visually describe how the plasticity model presented here works; see Figure 7. For implementation in a computer program, as is done in the present work, the formulation given in the present paper is straightforward. The model presented also includes the change of failure mode due to corrosion cracking, which was not included in Schlune (2006). Thus, in the present model, bond deterioration results due to a combination of the bond slip curve shift and the factor $k_{c o r}$. The present model can also be compared with the ones of Horrigmoe (2003) and Coronelli and Gambarova (2004). Horrigmoe (2003) scaled the bond stress-slip relationship for uncorroded bars to obtain a relationship for corroded bars, while Coronelli and Gambarova (2004) reduced the capacity and decreased the ductility. 


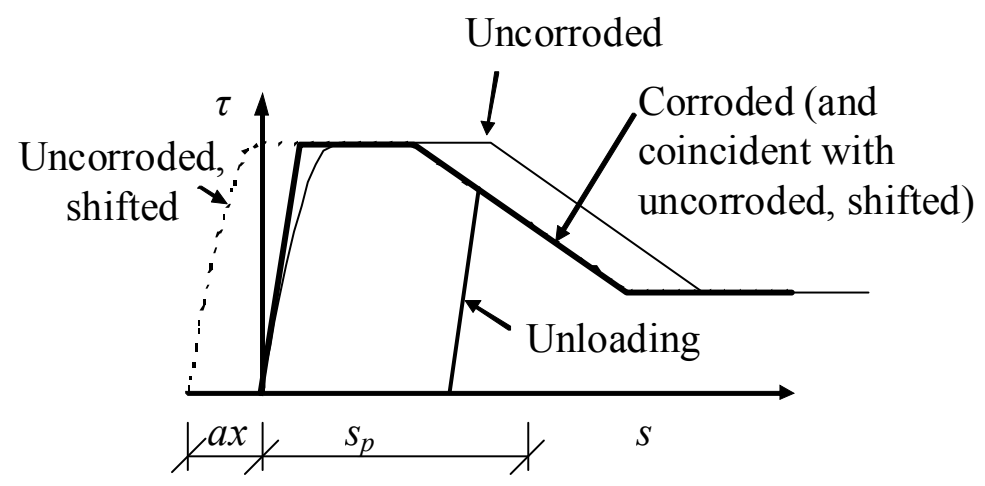

Figure 7. The proposed plasticity model is equivalent to using a "master curve" and adjusting the slip level to the amount of corrosion.

\section{Numerical implementation and computation of anchorage lengths}

For computation of the response of pull-out tests with short embedment lengths, constant shear stress and slip along the bar may be assumed; thus the 1D constitutive model can be applied directly. However, when the embedment length is long, the deformation of the rebar is not negligible. For these cases the 1D bond-slip differential equation must be solved, and since the bond-slip constitutive model is non-linear, the differential equation is also non-linear.

The computations in this paper were performed in Matlab, see http://www.Mathworks.com. The constitutive model, the differential equation and the boundary conditions were written into Matlab functions and supplied to a differential equation solver in Matlab called "BVP4C", which is used to compute the solution. The Matlab function BVP4C solves a system of ODEs (Ordinary Differential Equations) of the form $y^{\prime}=f(x, y)$ on the interval $[a, b]$, subject to general two-point boundary conditions of the form $b c(y(a), y(b))=0$ by collocation. The number of collacation points are automatically adapted by the program to reach a solution with specified accuracy.

For the practical inverse problem of computing the required anchorage length to sustain a given pull-out force, e.g. the yield force of the bar, an additional function was written in Matlab. The function starts with an initial guess for an upper and lower limit of the required anchorage length. The differential equation solver "BVP4C" is called and the responses, i.e. the load-displacement curves, for the assumed anchorage lengths are computed. If the maximum load obtained is close enough to the required capacity, the program terminates. Otherwise a new anchorage length is assumed, based on linear interpolation ("secant method") from the previous results. The response is computed and the termination criterion is checked. This procedure is iterated until the termination criterion is fulfilled and hence the required anchorage length is found.

\section{Comparison of results}

Results of the proposed 1D model were compared to results computed by the advanced 3D model as well as experimental results reported in literature. Experimental results from Almusallam et al. (1996) and Fang et al. (2004) were used. Note that the computed results are based on material data from the experiments and assumed model parameters, i.e. they are not calibrated to fit the data. Good bond conditions were assumed. It can be noted that the parameters used in the bond-slip 
model from CEB-FIP Model Code which this work is based on are mean values. However, the Model Code also states that the scatter is large; around $30 \%$ is mentioned. Considering this large scatter already for uncorroded specimens, a very large scatter can be expected when also corroded specimens are considered.

The anchorage length needed to anchor the yield force was calculated as described in the previous section, assuming that the yield stress was not influenced by corrosion, while the cross-sectional area of the reinforcement bar decreased assuming general corrosion. It should be noted that the bond loss that occurs when the reinforcement yields, see Engström (1992), is not included in these analyses. Thus, the calculated length will manage to anchor the yield force until yielding occurs; thereafter a pull-out failure will take place.

The advanced FE analyses that were used for comparison are briefly described in the following. In Lundgren (2005), a model of bond and corrosion to be used in detailed 3D finite element analyses was developed. The model was implemented in the finite element program Diana, and verified by comparisons to test results. In Lundgren (2007), this model was used in axisymmetric analyses to give an overview of how corrosion affects the bond in different typical cases. The behavior was again confirmed by comparison to test results from the literature. Here, results from the axisymmetric analyses are compared to results of the proposed 1D model.

The geometry in the finite element analyses is shown in Figure 8. The reinforcement had a diameter of $20 \mathrm{~mm}$, and yield strength of $500 \mathrm{MPa}$. The concrete compressive strength was $40 \mathrm{MPa}$, while the concrete cover and transverse reinforcement were varying. For every modeled geometry, several analyses were carried out. Each analysis started by modeling the corrosion process to varying corrosion levels. Thereafter, a deformation-controlled pull-out force was applied. The results used in this comparison are the consequent bond stress versus slip, where the bond stress has been calculated from the force by assuming constant bond stress along the bar. For more details, see Lundgren (2007).

To make sure that the proposed model can treat the most common cases regarding the confinement around the bar in a sufficiently good manner, the comparisons have been subdivided into four different cases (following the structure given in Lundgren (2007)):

1. with transverse reinforcement; cover cracks at uncorroded pull-out

2. with transverse reinforcement; cover does not crack at uncorroded pull-out

3. without transverse reinforcement; cover cracks at uncorroded pull-out

4. without transverse reinforcement; cover does not crack at uncorroded pull-out

An overview of all analyses is given in Table 2 . 
Table 2. Analysed cases

\begin{tabular}{|c|c|c|c|c|c|c|c|}
\hline $\begin{array}{c}\text { Case } \\
\text { type } \\
*\end{array}$ & $\begin{array}{c}\text { Transverse } \\
\text { reinforcement }\end{array}$ & $\begin{array}{c}\text { Cover } \\
\text { cracks at } \\
\text { uncorroded } \\
\text { pull-out }\end{array}$ & Compared to & $\begin{array}{c}\text { Cover to } \\
\text { bar } \\
\text { diameter } \\
\text { ratio }\end{array}$ & $\begin{array}{c}\text { Bar } \\
\text { diameter } \\
{[\mathrm{mm}]}\end{array}$ & $\begin{array}{c}\text { Concrete } \\
\text { strength } \\
{[\mathrm{MPa}]}\end{array}$ & $\begin{array}{c}\text { Steel } \\
\text { strength } \\
{[\mathrm{MPa}]}\end{array}$ \\
\hline 1 & $\begin{array}{c}2 \varnothing 6 \text { over } \\
80 \mathrm{~mm}\end{array}$ & yes & FE & 2.0 & 20 & 40 & 500 \\
\hline 1 & $\begin{array}{c}2 \varnothing 6 \mathrm{over} \\
80 \mathrm{~mm}\end{array}$ & yes & $\begin{array}{c}\text { Fang } \text { et al. } \\
(2004)\end{array}$ & 3.0 & 20 & 52.1 & 521 \\
\hline 2 & $\begin{array}{c}206 \mathrm{over} \\
80 \mathrm{~mm}\end{array}$ & no & FE & 4.0 & 20 & 40 & 500 \\
\hline 3 & - & yes & FE & 2.0 & 20 & 40 & 500 \\
\hline 3 & - & yes & $\begin{array}{c}\text { Fang } \text { et al. } \\
(2004)\end{array}$ & 3.0 & 20 & 52.1 & 521 \\
\hline 4 & - & no & FE & 4.0 & 20 & 40 & 500 \\
\hline 4 & - & no & $\begin{array}{c}\text { Almusallam } \\
\text { et al. }(1996)\end{array}$ & 5.3 & 12 & 30 & 600 \\
\hline
\end{tabular}

*Note:

1. with transverse reinforcement; cover cracks at uncorroded pull-out

2. with transverse reinforcement; cover does not crack at uncorroded pull-out

3. without transverse reinforcement; cover cracks at uncorroded pull-out

4. without transverse reinforcement; cover does not crack at uncorroded pull-out

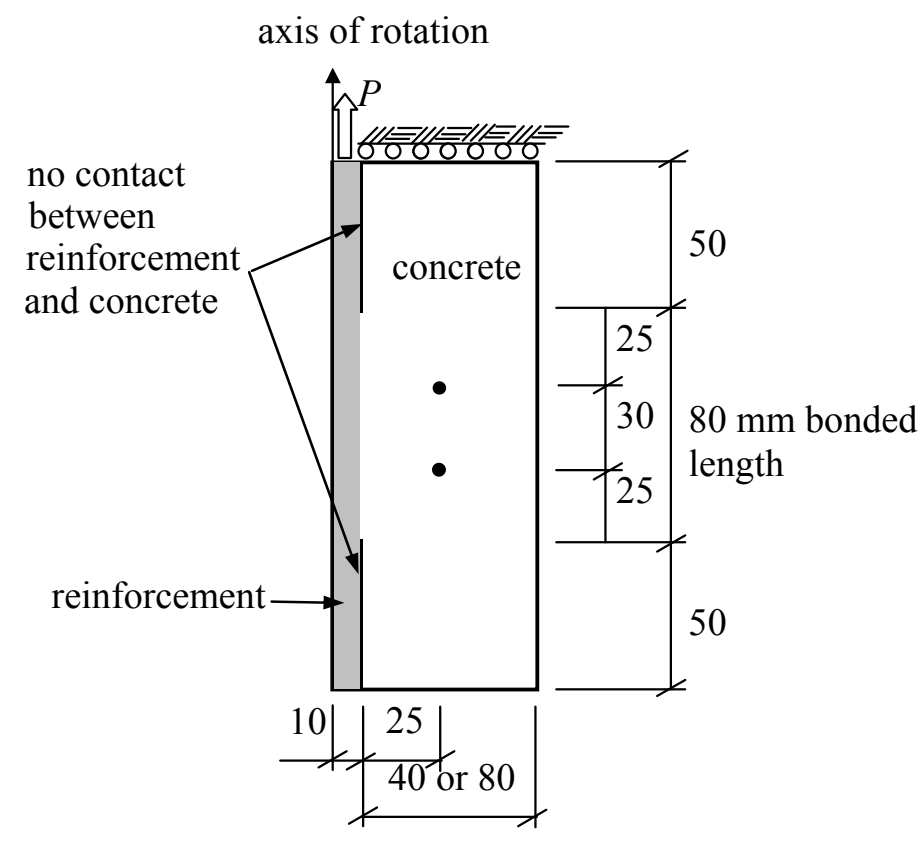

Figure 8. Dimensions and boundaries in the finite element analyses. Dimensions in $\mathrm{mm}$. 


\section{With transverse reinforcement; cover cracks at uncorroded pull-out}

In the finite element analyses with transverse reinforcement and cover cracking at uncorroded pull-out, the concrete cover was $40 \mathrm{~mm}$; thus the cover-to-diameter ratio was 2.0. The results from these analyses are compared to results of the $1 \mathrm{D}$ model in Figure 9. The drop in bond stress in the bond-slip curves from the FE analyses is due to a splitting crack reaching the outer surface; however, the transverse reinforcement kept the structure together, thus causing a ductile behavior for low corrosion levels. Regarding the bond capacity, it was about $15 \mathrm{MPa}$ for uncorroded reinforcement both in the FE analyses and in the 1D model. It was almost constant for varying corrosion levels in the FE analyses, while it slowly decreased for increasing corrosion levels in the 1D model. The bond capacity drop in the results of the 1D model for large corrosion penetrations $(500 \mu \mathrm{m})$ is due to that the corrosion alone causes a large effect on the hardening parameter $\kappa$, compare equation (16). In conclusion, the 1D model corresponds well for low corrosion levels, but is conservative for larger corrosion penetrations in this case. The same result is also seen when the anchorage lengths from the different analyses are compared.

Fang et al. (2004) made concentric pull-out tests with and without transverse reinforcement. The concrete cover was $60 \mathrm{~mm}$ and the reinforcement bar diameter was $20 \mathrm{~mm}$; thus the cover-to-diameter ratio was 3 . The yield strength of the main bars was $521 \mathrm{MPa}$. In the tests including transverse reinforcement, $2 \varnothing 6$ over an embedment length of $80 \mathrm{~mm}$ were used. Results from these experiments are compared to results of the 1D model in Figure 10. The drop in bond capacity in the 1D model at a corrosion penetration of $80 \mu \mathrm{m}$ is caused by cover cracking. Thereafter, the remaining capacity is mainly due to the stirrups. No similar drop can be seen in the experimental results; thus the confinement provided by the transverse reinforcement appears to be underestimated with the 1D model. A corresponding increase in anchorage length can be seen in the results from the 1D model.

In Lundgren (2005), it was concluded that for the case with transverse reinforcement and cover cracking at uncorroded pull-out, corrosion causes small bond decrease, or does not influence the bond capacity. The 1D model described here shows reductions in bond capacity; how large the reduction is depends on the relation between the cover and the amount of transverse reinforcement. It can be concluded that the 1D model gave conservative results. 


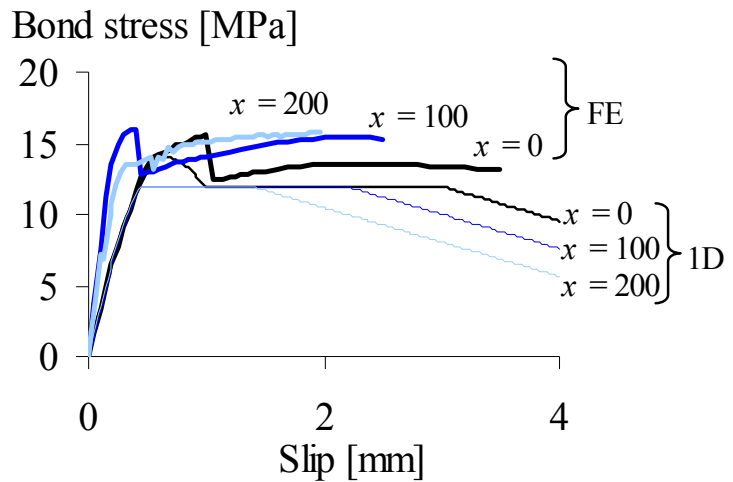

(a)

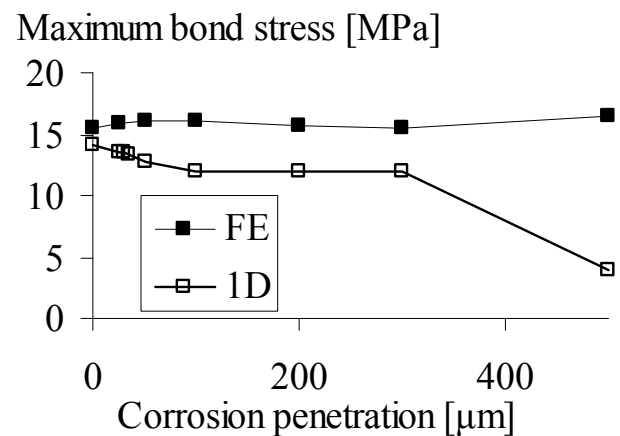

(b)

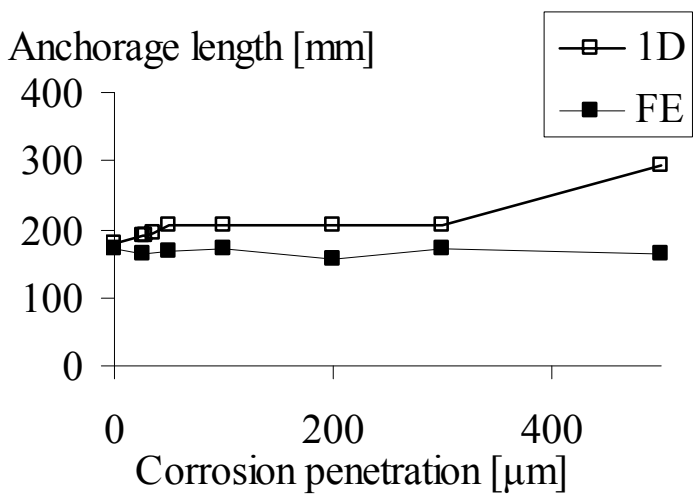

(c)

Figure 9. Comparison between results from FE analyses and 1D model for the case with $c / d=2$, transverse reinforcement and cover cracking at uncorroded pull-out. (a) Bond-slip curves for different corrosion penetrations (in $\mu \mathrm{m}$ ); (b) maximum bond stress versus corrosion penetration; and (c) anchorage length needed to anchor the yield force versus corrosion penetration. 


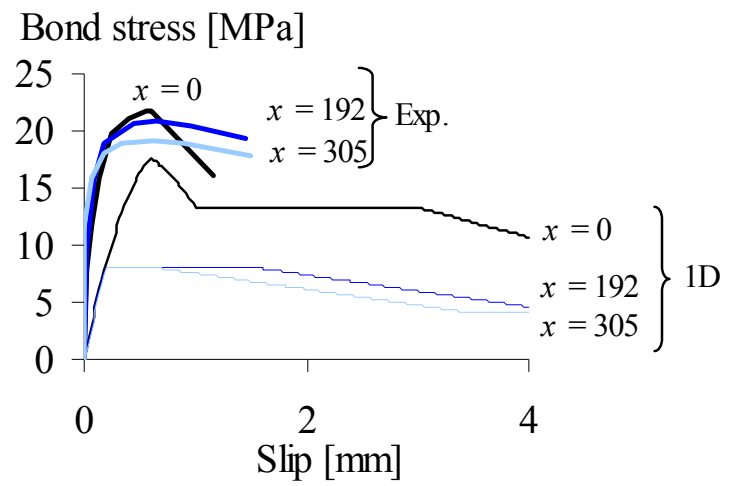

(a)

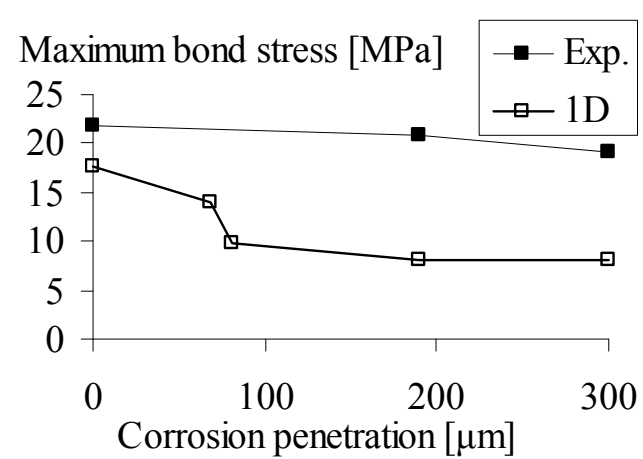

(b)

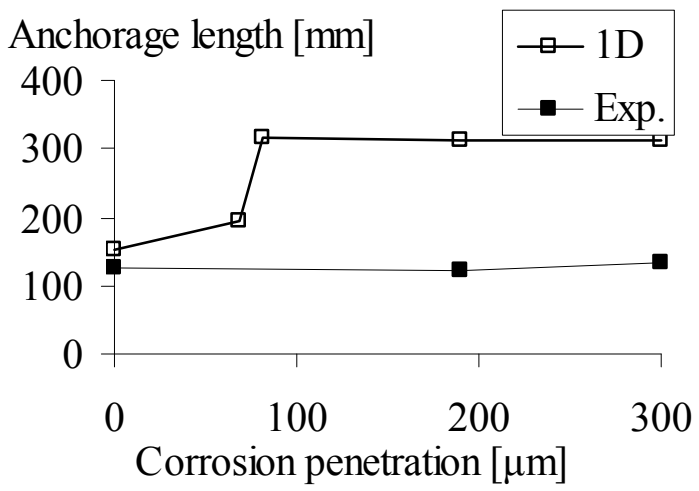

(c)

Figure 10. Comparison with experimental results by Fang et al. (2004), with $c / d=3$, ribbed bars and stirrups. (a) Bond-slip curves for different corrosion penetrations (in $\mu \mathrm{m}$ ); (b) maximum bond stress versus corrosion penetration; and (c) anchorage length needed to anchor the yield force versus corrosion penetration.

\section{With transverse reinforcement; cover does not crack at uncorroded pull-out}

The FE analyses with transverse reinforcement and no cover cracking at uncorroded pull-out were carried out with a concrete cover of $80 \mathrm{~mm}$, giving a cover-to-diameter ratio of 4.0. The results from these analyses are compared to results of the 1D model in Figure 11. Both the FE analyses and the 1D model resulted in ductile bond-slip behavior. Furthermore, the bond capacities decreased slightly and the anchorage length increased slightly when the cover was cracked; in the 1D model this occurred at a corrosion penetration of $100 \mu \mathrm{m}$, while in the FE analyses at around $270 \mu \mathrm{m}$. Again, it can be concluded that the 1D model gave results that are consistent with the physical behavior, and are on the safe side. Since no tests with transverse reinforcement and cover large enough to avoid cracking at uncorroded pull-out were found in the literature, no comparisons for this case to experimental results were made. 


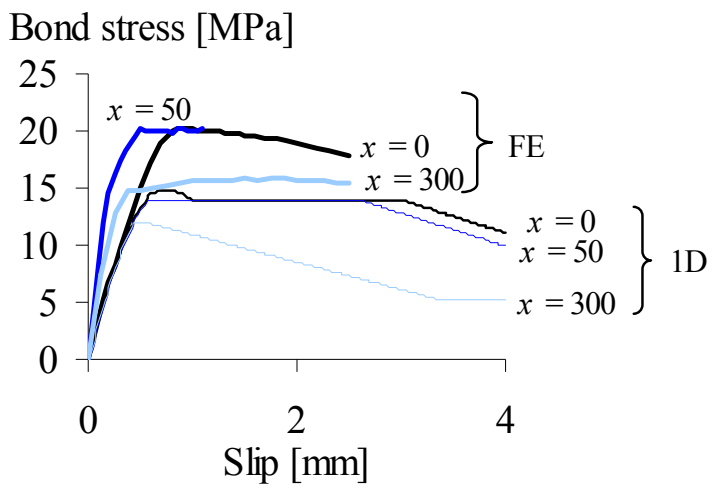

(a)

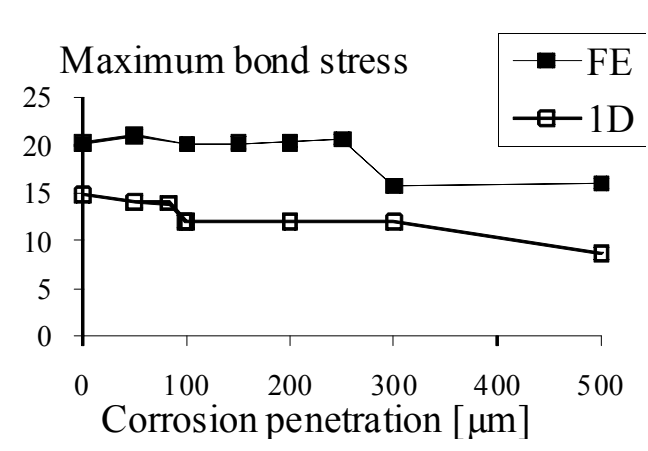

(b)

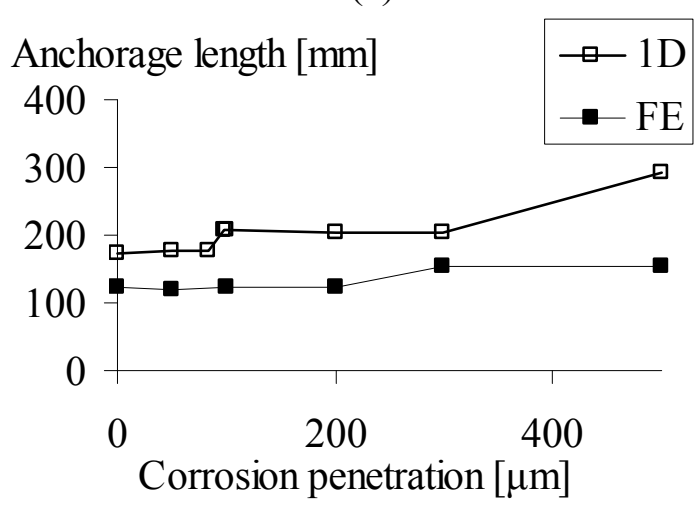

(c)

Figure 11. Comparison between results from FE analyses and $1 D$ model, with $c / d=4$, transverse reinforcement, no cover cracking at uncorroded pull-out. (a) Bond-slip curves for different corrosion penetrations (in $\mu \mathrm{m}$ ); (b) maximum bond stress versus corrosion penetration; and (c) anchorage length needed to anchor the yield force versus corrosion penetration.

\section{Without transverse reinforcement; cover cracks at uncorroded pull-out}

In axisymmetric FE models for this situation, the concrete cover was $40 \mathrm{~mm}$, i.e. similar to the corresponding case with transverse reinforcement. The results from these analyses are shown in Figure 12. In both FE and 1D model analyses, the bondslip response was brittle due to the lack of confinement, and became even more brittle for increasing corrosion levels. Also the bond capacity decreased with increasing corrosion penetrations. As can be seen in Figure 12, the agreement between the 1D model and the FE analyses is rather good. One difference is that for large corrosion penetrations, the bond capacity became almost zero in the FE analyses, resulting in very large anchorage length. Since the 1D model has a small residual bond capacity, the anchorage length became large for deep corrosion penetrations, although not as large as in the FE analysis results.

The concentric pull-out tests without transverse reinforcement made by Fang et al. (2004) were here used for comparison. The test specimens had a cover-todiameter ratio of 3. Results from these experiments are compared to results of the 1D model in Figure 13. The bond-slip behavior for uncorroded reinforcement is too ductile compared to the experimental results; however, already for low corrosion levels the failure mode became brittle and corresponded better. The drop in bond 
capacity in the 1D model at a corrosion penetration of $80 \mu \mathrm{m}$ is due to cover cracking. In the experiments, the decrease of bond capacity was more gradual.

In Lundgren (2005), it was concluded that for the case without transverse reinforcement and where the cover cracks at uncorroded pull-out, bond capacity decreases already for low corrosion levels. Here it was shown that the 1D model also gave this type of results.

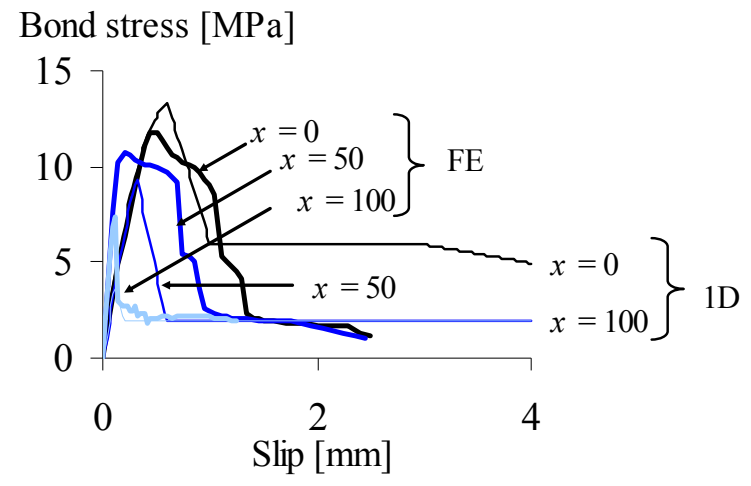

(a)

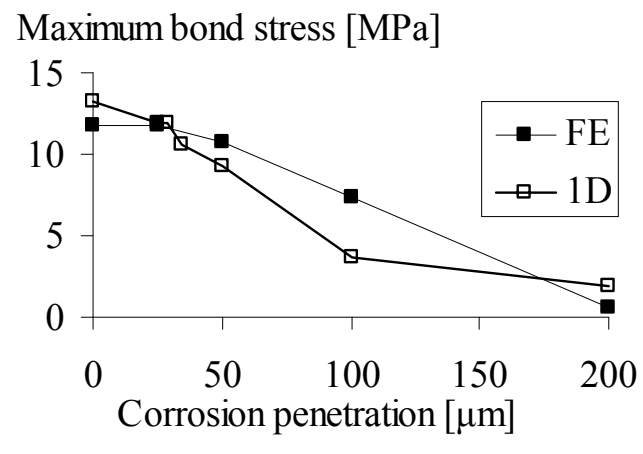

(b)

Anchorage length [mm]

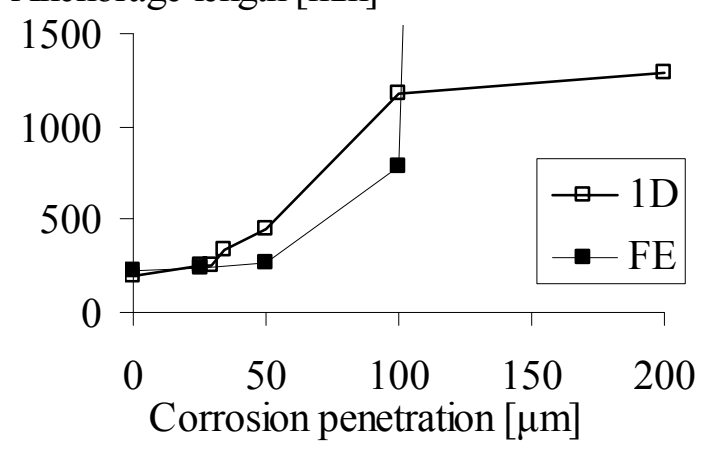

(c)

Figure 12. Comparison between results from FE analyses and $1 D$ model, with $c / d=2$, without transverse reinforcement, cover cracks at uncorroded pull-out. (a) Bond-slip curves for different corrosion penetrations (in $\mu m$ ); (b) maximum bond stress versus corrosion penetration; and (c) anchorage length needed to anchor the yield force versus corrosion penetration. 


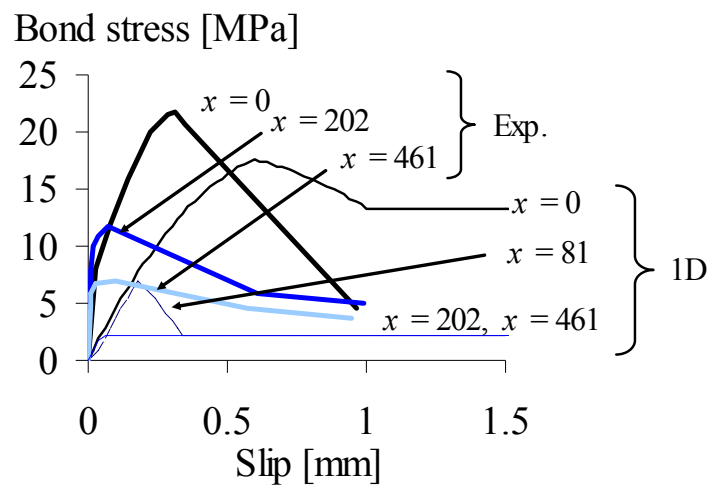

(a)

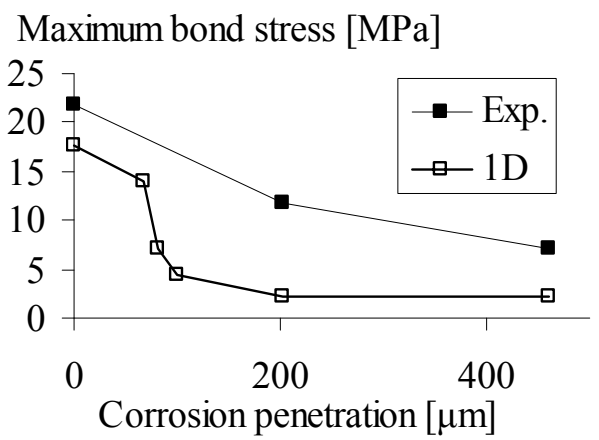

(b)

Anchorage length [mm]

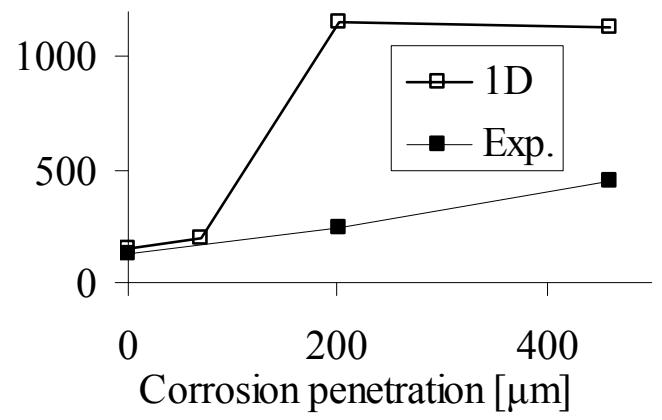

(c)

Figure 13. Comparison with experimental results by Fang et al. (2004), with c/d=3, ribbed bars without stirrups. (a) Bond-slip curves for different corrosion penetrations (in $\mu \mathrm{m}$ ); (b) maximum bond stress versus corrosion penetration; and (c) anchorage length needed to anchor the yield force versus corrosion penetration.

\section{Without transverse reinforcement; cover does not crack at uncorroded pull-out}

In the FE analyses without transverse reinforcement and no cover cracking at uncorroded pull-out, corrosion alone cracked the cover at a corrosion penetration around $215 \mu \mathrm{m}$. This can be compared to the 1D model, which resulted in corrosion cracking at a corrosion penetration of $98 \mu \mathrm{m}$. Corrosion cracking caused a sharp drop in bond capacity in both types of analyses, as can be seen in Figure 14. Furthermore, the bond-slip behavior changes from ductile to brittle at corrosion cracking, also in both types of analyses. The difference in corrosion penetration at cracking is explained by the geometry of the modeled specimen in the FE analysis (see Figure 8); the concrete outside the bonded zone kept the structure together, and thus delayed corrosion cracking. This effect is not included in the 1D model. For the anchorage length, the behavior is similar to the case without transverse reinforcement and no cover cracking at uncorroded pull-out. Thus, for large corrosion penetrations, the bond capacity became almost zero in the FE analyses, resulting in very large anchorage length. Since the 1D model had a small residual bond capacity, the anchorage length became large for deep corrosion penetrations, although not as large as in the FE analysis results. 


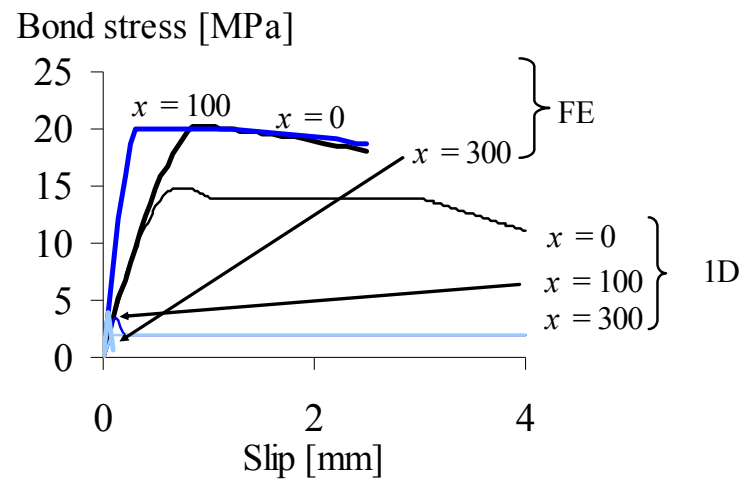

(a)

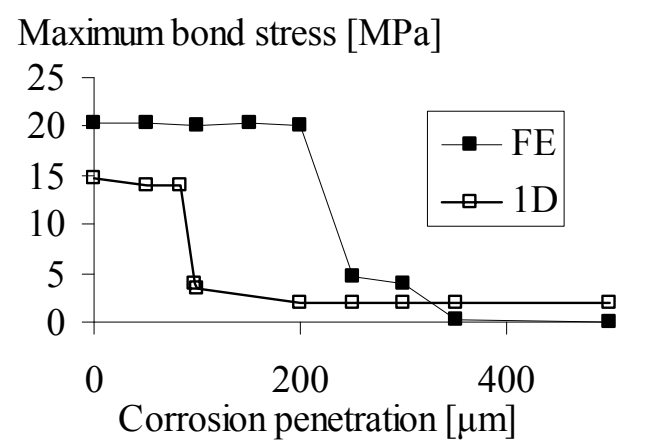

(b)

Anchorage length [mm]

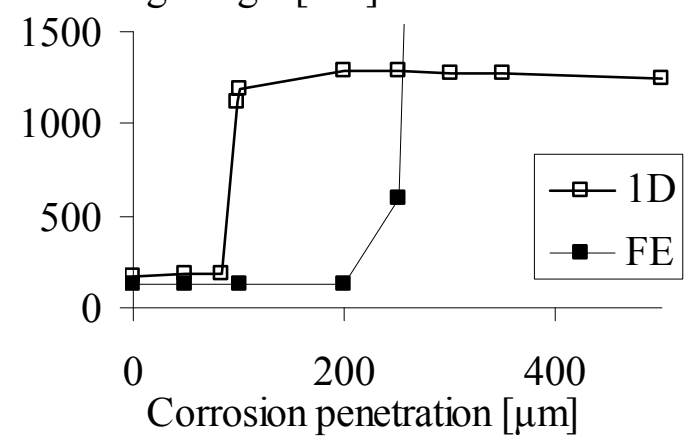

(c)

Figure 14. Comparison between results from FE analyses and $1 D$ model, with $c / d=4$, without transverse reinforcement, no cover cracking at uncorroded pullout. (a) Bond-slip curves for different corrosion penetrations (in $\mu \mathrm{m}$ ); (b) maximum bond stress versus corrosion penetration; and (c) anchorage length needed to anchor the yield force versus corrosion penetration.

Almusallam et al. (1996) have carried out cantilever bond tests with large concrete covers and no active transverse reinforcement. Their specimens were $152 * 254 * 279 \mathrm{~mm}^{3}$, and had a $12 \mathrm{~mm}$ diameter bar with $102 \mathrm{~mm}$ embedment length. They were subjected to accelerated corrosion at varying levels; thereafter bond tests were conducted, and the corrosion penetration was measured by the weight loss method. The yield strength of the bar was here assumed to be $600 \mathrm{MPa}$. Again, corrosion cracking caused a sharp drop in bond capacity, both in experiments and in the 1D model; see Figure 15. Furthermore, the bond-slip behavior changed from ductile to brittle at corrosion cracking, also both in experiments and in the 1D model. In the tests, a first crack was noted at a corrosion penetration of $140 \mu \mathrm{m}$, and at a corrosion penetration of $200 \mu \mathrm{m}$, a second crack reached the edge. In the 1D model, corrosion cracking occurred for a lower corrosion penetration, around $90 \mu \mathrm{m}$, thus causing a decrease in bond capacity and an increase in anchorage length. For large corrosion penetrations, the anchorage length is slowly decreasing. This is due to the area decrease of the reinforcement bar, which decreases the yield force that should be anchored. 


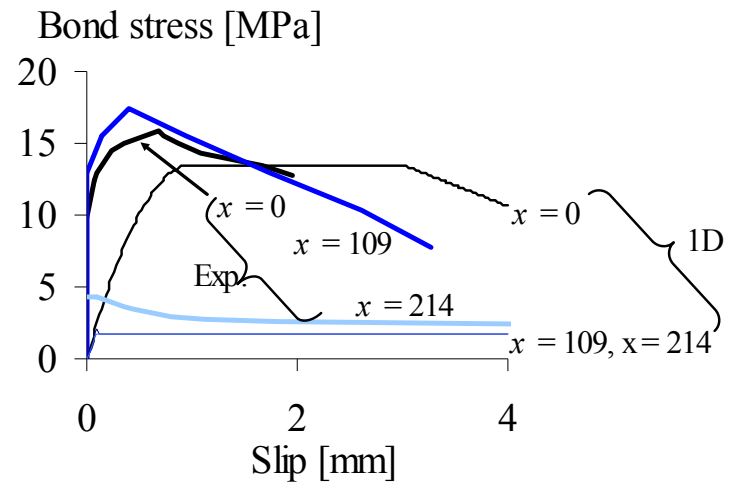

(a)

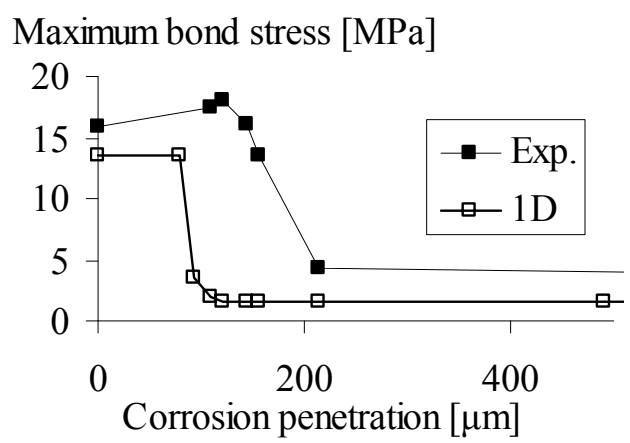

(b)

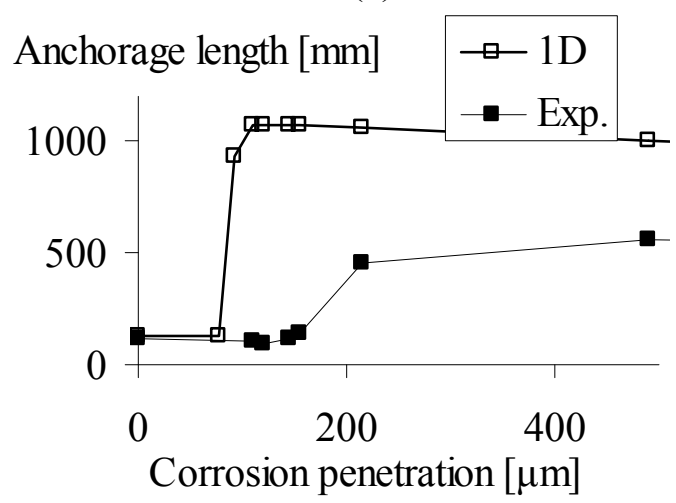

(c)

Figure 15. Comparison with experimental results from Almusallam et al. (1996) with $c / d=5.3$. (a) Bond-slip curves for different corrosion penetrations (in $\mu \mathrm{m}$ ); (b) maximum bond stress versus corrosion penetration; and (c) anchorage length needed to anchor the yield force versus corrosion penetration.

In Lundgren (2005), it was concluded that for this case, corrosion causes small increase in bond capacity until the cover cracks; thereafter the bond capacity decreases abruptly. Also the ductility decreases after cover cracking. The suggested 1D model was shown to give results that are consistent with this physical behavior, and in most cases they are on the safe side. However, for large corrosion penetrations, the calculated anchorage length might not be on the safe side. This is due to the residual bond capacity from the CEB-FIP Model Code 1990, which in the present model will remain also for very large corrosion levels. It can be questioned whether that is really reasonable.

\section{Conclusions}

The paper has presented an analytical 1D model for bond-slip response of corroded reinforcement. The proposed model is an extension of the 1D bond-slip model given in the CEB-FIP Model Code 1990. The model is practically applicable for structural analyses to determine the load-carrying capacity of corroded structures.

The capability of the model was examined by comparisons to experimental results as well as to results from an advanced 3D finite element model. From this study, the following conclusions can be drawn:

- The computed results, in terms of bond-slip curves, maximum bond stress and anchorage length needed to anchor the yield force, give a qualitatively 
reasonable response compared to the experiments; i.e. the results are consistent with the physical behavior.

- The suggested model gives results that are on the safe side for most cases. It should be noted, however, that for large corrosion penetrations and no or small amount of transverse reinforcement, the calculated anchorage length might not be on the safe side. Thus, if the concrete cover has spalled off totally, it might not be safe to use the model to estimate required anchorage lengths.

- For large corrosion penetrations, e.g. $x$ greater than 400-500 microns, where the model may give non-conservative results, see point above, the model may need refinements to take into account interface deterioration such as rib reduction and subsequent change of the friction angle.

Future work will concentrate on testing the model in applications to beams that fail due to bond. Furthermore, investigations concerning the anchorage length for large corrosion penetrations are needed. 


\section{Notation}

$A_{s w}$ area of transverse reinforcement

$D$ bond stiffness

$E$ Young's modulus

$L$ length

$a$ parameter relating the corrosion penetration to the hardening parameter $c$ concrete cover

$d$ reinforcement bar diameter

$f_{c c}$ concrete compressive strength

$k_{A s w}$ factor depending on the amount of transverse reinforcement

$k_{c o r}$ factor for corroded case

$k_{c / d}$ factor depending on the cover-to-bar-diameter ratio

$k_{\text {uncor }}$ factor for uncorroded case

$s$ slip; distance between stirrups

$s_{1}, s_{2}$ and $s_{3}$ slip values, model parameters

$s_{p}$ plastic slip

$x$ coordinate along reinforcement bar; corrosion penetration

$x_{\mathrm{cr}}$ corrosion penetration that causes cover cracking

$u$ displacement of the bar

$u_{L}$ prescribed displacement

$\varepsilon$ strain

$\kappa$ hardening parameter

$\sigma$ stress in the rebar

$\tau$ bond stress

$\tau_{b}$ bond strength

$\tau_{b, \text { conf. }}$ bond strength for "confined case"

$\tau_{b, \text { unconf. }}$ bond strength for "unconfined case"

$\tau_{f}$ remaining bond strength, model parameter

$\tau_{\max }$ maximum bond strength, model parameter

$\tau_{\max , \text { conf. }}$ maximum bond strength for confined concrete 


\section{References}

Al-Sulaimani, G.J., Kaleemullah, M., Basunbul, I.A. \& Rasheeduzzafar, 1990. Influence of corrosion and cracking on bond behavior and strength of reinforced concrete members. ACI Structural Journal, 87 (2), 220-231.

Almusallam, A.A., Al-Gahtani, A.S. \& Aziz, A.R., 1996. Effect of reinforcement corrosion on bond strength. Construction and Building Materials, 10 (2), 123129.

Andrade, C., Alonso, C. \& Molina, F.J., 1993. Cover cracking as a function of bar corrosion.1. Experimental test. Materials and Structures, 26 (162), 453-464.

Http://www.Mathworks.Com/ [online]. Accessed 2008-02-19

Berra, M., Castellani, A., Coronelli, D., Zanni, S. \& Zhang, G., 2003. Steel-concrete bond deterioration due to corrosion: Finite-element analysis for different confinement levels. Magazine of Concrete Research, 55 (3), 237-247.

Bhargava, K., Ghosh, A.K., Mori, Y. \& Ramanujam, S., 2008. Suggested empirical models for corrosion-induced bond degradation in reinforced concrete. Journal of Structural Engineering, 134 (2), 221-230.

Cabrera, J.G. \& Ghoddoussi, P., Year. The effect of reinforcement corrosion on the strength of the steel/concrete "Bond"ed.^eds. Bond in Concrete, Proceedings of an International Conference, Riga: CEB, 10-11 - 10-24.

Ceb, 1993. Ceb-fip model code 1990 Lausanne, Switzerland: Bulletin d'Information $213 / 214$.

Coronelli, D. and Gambarova, P, 2004. Structural Assessment of Corroded Reinforced Concrete Beams: Modeling Guidelines. ASCE Journal of Structural Engineering, August 2004, 1214-1224.

Coronelli, D., 2002. Corrosion cracking and bond strength modeling for corroded bars in reinforced concrete. ACI Structural Journal, 99 (3), 267-276.

Duracrete, 2000. General guidelines for durability design and redesign. Duracrete. Probabilistic performance based durability design of concrete structures. The European Union - Brite EuRam III.

Engström, B., 1992. Ductility of tie connections in precast structures. Ph.D. Thesis (Ph.D. ). Chalmers University of Technology.

Fang, C., Lundgren, K., Chen, L. \& Zhu, C., 2004. Corrosion influence on bond in reinforced concrete. Cement and Concrete Research, 34 (11), 2159-2167.

Fib, 2000. Bond of reinforcement in concrete, state-of-art report. Lausanne: Fédération internationale du béton, prepared by Task Group Bond Models, 427.

Ghandehari, M., Zulli, M. \& Shah, S.P., 2000. Influence of corrosion on bond degradation in reinforced concreteed. Proceedings EM2000, Fourteenth Engineering Mechanics Conference, Austin, Texas: ASCE.

Horrigmoe, G., 2003: Assessment of the performance and safety of deteriorated concrete structures, Concrete Solutions (eds. M. Grantham, F. Rendell, R. 
Jauberthie and C. Lanos), GR Technologies, New Barnet, U.K., 2003, Vol. 1, 209-223.

Lee, H.-S., Noguchi, T. \& Tomosawa, F., 2002. Evaluation of the bond properties between concrete and reinforcement as a function of the degree of reinforcement corrosion. Cement and Concrete Research, 32 (8), 1313-1318.

Liu, Y.P. \& Weyers, R.E., 1998. Modeling the time-to-corrosion cracking in chloride contaminated reinforced concrete structures. ACI Materials Journal, 95 (6), 675-681.

Lundgren, K., 2005. Bond between ribbed bars and concrete. Part 2: The effect of corrosion. Magazine of Concrete Research, 57 (7), 383-395.

Lundgren, K., 2007. Effect of corrosion on the bond between steel and concrete: An overview. Magazine of Concrete Research, 59 (6), 447-461.

Lundgren, K., Roman, A.S.S., Schlune, H., Hanjari, K.Z. \& Kettil, P., Year. Effects on bond of reinforcement corrosion. In: Ferreira, R.M., J.Gulikers \& Andrade, C., ed.^eds. International RILEM workshop on Integral Service Life Modeling of Concrete Structures, 5-6 November 2007, Guimaraes, Portugal: RILEM Publications S.A.R.L, 231-238.

Magnusson, J., 2000. Bond and anchorage of ribbed bars in high-strength concrete. $\mathrm{Ph}$.D. Thesis (Ph. D.). Chalmers University of Technology.

Rasheeduzzafar, Al-Saadoun, S.S. \& Al-Gahtani, A.S., 1992. Corrosion cracking in relation to bar diameter, cover, and concrete quality. Journal of Materials in Civil Engineering, 4 (4), 327-342.

Schlune, H., 2006. Bond of corroded reinforcement: Analytical description of the bond-slip response. M. Sc. Thesis 2006:107 (M. Sc.). Chalmers University of Technology.

Soto San Roman, A., 2006. Bond behaviour of corroded reinforcement: Fe-modelling and parameter study. M. Sc. Thesis 2006:94 (M. Sc.). Chalmers University of Technology.

Wang, X. \& Liu, X., 2006. Bond strength modeling for corroded reinforcements. Construction and Building Materials, 20 (3), 177-186. 